7. Reprod. Fertil. (1965) 10, 261-262

BRIEF COMMUNICATION

\title{
TRANSAMINASES IN THE EPIDIDYMAL FLUID OF THE RAM*
}

\author{
EUGENIA ALUMOT AND H. SGHINDLER
}

National and University Institute of Agriculture, Rehovot, Israel

(Received 18th Fanuary 1965)

In a study of the composition of the epididymal fluid of rams, attention was given to the fact that nitrogen compounds constitute a great part of the dry matter and that so far seventeen free amino acids have been detected in the fluid (Ch. Neumark, unpublished data). It was therefore deemed of interest to study the enzymes of their metabolism. Two principal transaminases were investigated: glutamic-aspartic transaminase (GOT) and glutamic-alanine transaminase (GPT). The presence of these enzymes has been established in human, bovine and rabbit seminal plasma (Flipse, 1960; Povoa \& Villela, 1960; Gregoire, Rakoff \& Ward, 1961), but no report on their presence in the epididymal fluid was found in the literature.

\section{TABLE 1}

TRANSAMINATION ACTIVITY IN RAM EPIDIDYMAL FLUID, SEMINAL PLASMA AND BLOOD SERUM ( $\mu$ MOLES PYRUVATE/ML/HR)

\begin{tabular}{c|c|c|c|c|c|c|c}
\hline \multirow{2}{*}{$\begin{array}{c}\text { Sample } \\
\text { No. }\end{array}$} & \multicolumn{2}{|c|}{ Epididymal fuid } & \multicolumn{2}{c|}{ Seminal plasma } & \multicolumn{2}{c}{ Blood serum } \\
\cline { 2 - 6 } \cline { 5 - 7 } & GOT & GPT & GOT & GPT & GOT & GPT \\
\hline 1 & 20 & Traces & 25 & 0 & $2 \cdot 8$ & $1 \cdot 4$ \\
2 & 32 & $5 \cdot 0$ & 26 & 0 & $3 \cdot 0$ & $1 \cdot 5$ \\
3 & 11 & 0 & 33 & Traces & $2 \cdot 0$ & $0 \cdot 6$ \\
4 & 11 & 0 & 20 & 0 & - & - \\
5 & - & - & 26 & Traces & - & - \\
\hline
\end{tabular}

Epididymal fluid obtained from fistulated rams (A. Tadmor \& H. Schindler, unpublished information) served for the enzyme determination. For comparison, the enzymatic activity was also investigated in the seminal plasma and blood serum of rams.

The procedure of Reitman \& Frankel (1957) for the determination of transaminases in blood serum was adapted to the epididymal fluid as follows: samples of epididymal semen were centrifuged with equal volumes of isotonic $(0 \cdot 15 \mathrm{M})$ phosphate buffer at $\mathrm{pH} \mathrm{7 \cdot 3}$; the supernatant was diluted with 4 vol. of distilled water, $0.2 \mathrm{ml}$ of which (corresponding to $0.02 \mathrm{ml}$ of the original

* Contribution from the National and University Institute of Agriculture, Rehovot, Israel; 1965 series, No. 813-E. 
sample) were taken for the enzyme determinations. The average dry matter content of the epididymal fluid was $8.0 \%$ and nitrogen content was $0.7 \%$.

The enzyme activity data are presented in Table 1 . The results are reported in micromoles of pyruvate formed $/ 1 \mathrm{ml}$ original fluid/ $\mathrm{hr}$. (In the case of GOT the oxaloacetate formed was determined as pyruvate, after decarboxylation.)

It can be seen from Table 1 that the activity of GOT is about ten times greater in the epididymal fluid and seminal plasma than in the blood serum. On the other hand, almost no GPT activity was detected in the epididymal fluid and seminal plasma, with the exception of one sample. GPT was tested also in an undiluted sample of epididymal fluid with the same negative results.

As far as the results can be compared, owing to the diversity of units of activity, the data reported in this study for GOT are of the same order of magnitude as the values found by other authors. Gregoire $e t$ al. (1961) found that in normal human seminal plasma GOT activity was about twenty times greater than in blood serum, Povoa \& Villela (1960) found it ten times greater, and Flipse (1960) found that the GPT activity in bovine seminal plasma was very weak as compared to the GOT activity, which was forty times greater.

The fact that GOT transaminase in the epididymal fluid exerts an activity exceeding by many times that found in the blood and that, on the other hand, GPT is found only in traces in all but one case, despite its presence in the blood, points to the existence of a transaminase mechanism in the epididymal fluid, independent of that in the blood. It appears that the epididymal fluid is one of the sources of GOT in the seminal plasma.

This research has been financed in part by a grant made by the United States Department of Agriculture, under P.L. 480.

\section{REFERENCES}

Fuipse, R. J. (1960) Metabolism of bovine semen. IX. Glutamic-oxaloacetic and glutamic-pyruvic transaminase activities. 7. Dairy Sci. 43, 773.

GREGolRe, A. T., RAKoff, A. E. \& WARD, K. (1961) Glutamic-oxaloacetic transaminase in semen of human, bull, and rabbit seminal plasma. Int. F. Fertil. 6, 73.

Povoa, H. \& Villela, G. G. (1960) Transaminase in seminal plasma of man. Experientia, 16, 199.

ReItMan, S. \& Frankel, S. (1957) Determination of glutamic-oxaloacetic and glutamic-pyruvic transaminases. Amer. F. clin. Path. 28, 56. 